Article

\title{
Evaluation of an Algorithm for Testis-Sparing Surgery in Boys with Testicular Tumors: A Retrospective Cohort Study
}

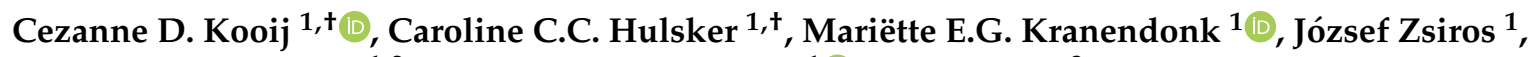 \\ Annemieke S. Littooij ${ }^{1,2}$, Leendert H.J. Looijenga ${ }^{1}{ }^{\mathbb{D}}$, Aart J. Klijn ${ }^{3}$ and \\ Annelies M.C. Mavinkurve-Groothuis ${ }^{1, * \mathbb{D}}$ \\ 1 Princess Máxima Center for Pediatric Oncology, 3584 Utrecht, The Netherlands; \\ C.D.Kooij-2@prinsesmaximacentrum.nl (C.D.K.); C.C.C.Hulsker@prinsesmaximacentrum.nl (C.C.C.H.); \\ M.E.G.Kranendonk-2@umcutrecht.nl (M.E.G.K.); J.Zsiros@prinsesmaximacentrum.nl (J.Z.); \\ A.S.Littooij-2@umcutrecht.nl (A.S.L.); L.Looijenga@prinsesmaximacentrum.nl (L.H.J.L.) \\ 2 Department of Radiology and Nuclear Medicine, University Medical Center Utrecht, 3584 Utrecht, \\ The Netherlands \\ 3 Department of Pediatric Urology, University Medical Center Utrecht, 3584 Utrecht, The Netherlands; \\ A.J.Klijn@umcutrecht.nl \\ * Correspondence: a.m.c.mavinkurve-groothuis@prinsesmaximacentrum.nl; Tel.: +31-889-727-272 \\ + These authors contributed equally.
}

\section{check for}

updates

Citation: Kooij, C.D.; Hulsker, C.C.C.; Kranendonk, M.E.G.; Zsiros, J.;

Littooij, A.S.; Looijenga, L.H.J.; Klijn,

A.J.; Mavinkurve-Groothuis, A.M.C.

Evaluation of an Algorithm for

Testis-Sparing Surgery in Boys with Testicular Tumors: A Retrospective Cohort Study. Surgeries 2021, 2, 9-19. https://doi.org/10.3390/

surgeries 2010002

Received: 17 December 2020

Accepted: 6 January 2021

Published: 11 January 2021

Publisher's Note: MDPI stays neutral with regard to jurisdictional clai$\mathrm{ms}$ in published maps and institutional affiliations.

Copyright: $\odot 2021$ by the authors. Licensee MDPI, Basel, Switzerland. This article is an open access article distributed under the terms and conditions of the Creative Commons Attribution (CC BY) license (https:// creativecommons.org/licenses/by/ $4.0 /)$.

\begin{abstract}
Aim: This study reports surgical treatment and its outcome for boys with a testicular tumor, in order to analyze the considerations of testis-sparing surgery (TSS) and investigate whether, in retrospect, treatment was according to a recently developed algorithm. Methods: We retrospectively reviewed boys with testicular tumors who underwent surgical treatment between January 2000 and June 2020 at the Wilhelmina's Children's Hospital and the Princess Máxima Center for Pediatric Oncology, The Netherlands. Medical records were searched for clinical characteristics and outcome. Results: We identified 31 boys (median age $=5.5$ years) with a testicular tumor, 26 germ cell tumors (GCTs), four sex cord-stromal tumors, and one gonadoblastoma. Seventeen boys (median age $=1.5$ years) had malignant and 14 (median age $=3.6$ years) had benign tumors Four boys with benign GCTs were treated with TSS, 25 with radical inguinal orchiectomy (RIO), and 2 with scrotal orchiectomy. No recurrence or testicular atrophy was reported. All boys with benign testicular tumors were treated as suggested by the algorithm, except for one boy treated with RIO. Conclusion: Retrospective analysis of surgical treatment of prepubertal boys with benign testicular tumors showed that TSS appears to be safe, and should be considered based on clinicoradiological data, in line with our algorithm.
\end{abstract}

Keywords: testis-sparing surgery; testicular tumors; pediatric; recurrence; testicular atrophy; algorithm

\section{Introduction}

Testicular tumors are rare, accounting for approximately $1 \%$ of cancers in males [1,2]. Although in men between 14 and 44 years of age, testicular cancer is the most common malignancy [3], testicular tumors constitute only $1 \%$ to $2 \%$ of all solid tumors in the pediatric population [4]. In children, it shows a bimodal age distribution: in the first three years of life and during or just after puberty, often referred to as prepubertal and (post)pubertal, respectively $[5,6]$. Prepubertal testicular tumors show a lower incidence rate and appear to have a distinctive biology compared to those of (post)pubertal age [7]. Testicular germ cell tumors (GCTs) form the largest group of testicular tumors. Type I testicular GCTs usually occur in prepubertal children, and are not germ cell neoplasia in situ (GCNIS)-associated tumors, with initial benign behavior. GCNIS is the non-invasive precursor cell of origin for type II testicular GCTs, which are malignant and usually postpubertal $[6,8,9]$. Sex cord-stromal tumors (SCSTs) comprise a smaller group of testicular tumors and are mainly 
benign [10]. (Post)pubertal boys mainly suffer from malignant type II GCTs, predominantly mixed non-seminomatous GCTs (MGCT) [5]. Nonetheless, the majority of prepubertal testicular tumors appear to be benign after pathological evaluation [11]. Age can even be considered as the most important prognostic factor in pediatric GCTs, according to the largest retrospective evaluation of the Maligne Keimzelltumoren (MAKEI) dataset [12].

Before surgery, and hence before histological diagnosis, the distinction between benign and malignant tumors is based on diagnostic tools like ultrasonographic (US) imaging and serum tumor markers (STMs). To date, radical inguinal orchiectomy (RIO) is considered the standard surgical approach for unilateral testicular tumors [4]. Scrotal violations seem to carry a higher risk of recurrence than RIO, and are therefore not a preferable approach for the initial treatment of testicular tumors [13]. To minimize the risk of overtreatment of benign tumors, especially in prepubertal boys, testis-sparing surgery (TSS) is increasingly being considered [14]. TSS is performed through an inguinal incision; the testis is subsequently mobilized, and the tumor is excised with a margin of salvageable testicular parenchyma [15]. While RIO is associated with psychological and cosmetic consequences, this is limited in case of TSS intervention [16]. Moreover, unilateral orchiectomy may even lead to a decreased fertility [17]. In patients with a solitary testis pre-operation, TSS is recommended to preserve Leydig cell function, and thereby testosterone production [3]. Although TSS is increasingly used in the treatment of benign tumors, it remains unclear to what extent this approach is performed in current practice. In addition, no guidelines or best practice are available [18]. In our recent systematic review, we concluded that TSS is a safe treatment option for prepubertal boys with benign GCTs and low-grade sex cord-stromal tumors (SCST) [19]. We suggested the application of an algorithm for determination of the appropriate surgical treatment in prepubertal ( $<12$ years of age) boys with testicular tumors. We hypothesize that, in retrospect, most of the boys in our center are treated according to this algorithm.

In this study, we report the retrospective evaluation of surgical treatment and the outcome for children with a testicular tumor treated in two pediatric centers over the past 20 years. We aim to investigate the considerations regarding performance of TSS and to investigate whether patients, in retrospect, have been surgically treated according to the algorithm proposed in our recent systematic review [19].

\section{Materials and Methods}

This retrospective cohort study was performed at the Wilhelmina Children's Hospital and the Princess Máxima Center for Pediatric Oncology, Utrecht, The Netherlands. This study was approved by the Local Ethics Committee. Children are treated at these centers until the age of 18 years. Boys with testicular tumors who underwent surgical excision between January 2000 and June 2020 were collected from the nationwide network and registry of histopathology in the Netherlands (PALGA), which digitally archives all pathology excerpts [20]. Pathology results from testicular tissue obtained from both centers were assessed for the presence of a testicular tumor. Both benign and malignant testicular tumors were included. Paratesticular tumors and hematolymphoid tumors were excluded. Medical records associated with the obtained pathology results were searched for clinical characteristics, e.g., age at presentation and thereby pubertal status; main presenting symptoms; STMs; imaging techniques, including US imaging, computed tomography (CT), and magnetic resonance imaging (MRI); surgical approach; use of frozen section examination (FSE); adjuvant chemotherapy; stage of disease; final histopathological diagnosis; and outcome.

Alpha fetoprotein (AFP) and beta human chorionic gonadotropin (bHCG) were reported as STMs. AFP was assessed based on age-specific ranges. Staging of testicular tumors was based on the Lugano classification. The assessment of outcomes included testicular atrophy, adverse events, relapse or recurrence, and survival. Follow-up was based on the last recorded date of an appointment for examination. Age and follow-up were reported in years. 
As an additional analysis, boys with potentially benign histopathology and their diagnostic findings were noted to assess the eligibility and considerations for TSS, using the algorithm shown in Figure 1.

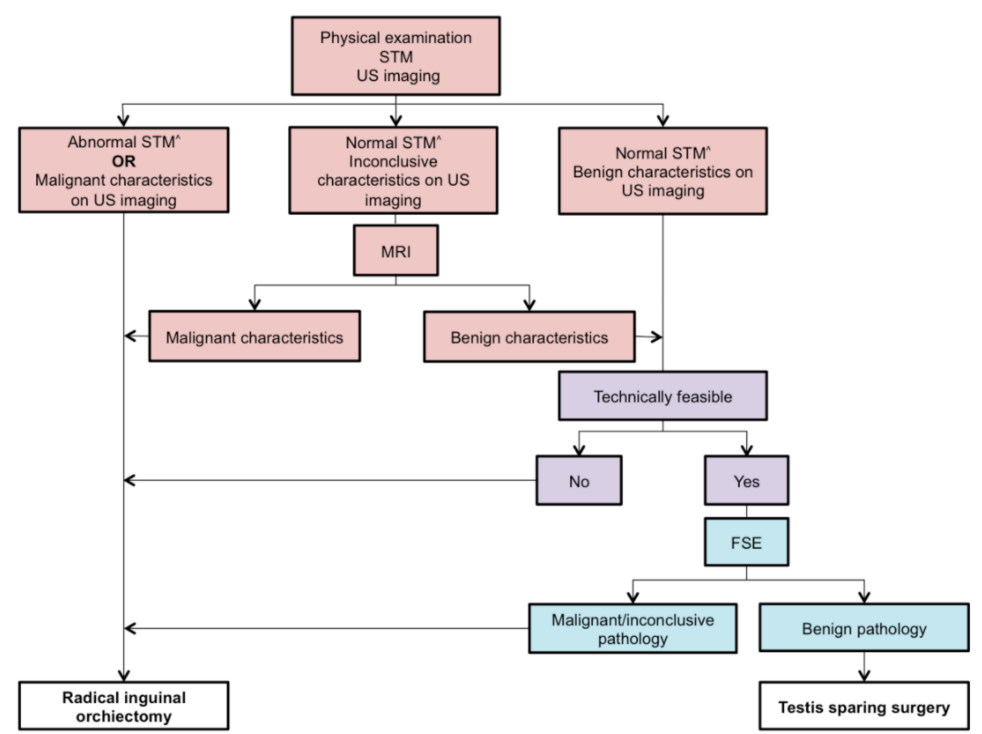

Figure 1. The algorithm for surgical approach in prepubertal boys less than 12 years of age with testicular tumors, based on the results of our recent systematic review. STM: serum tumor marker; FSE: frozen section examination; ${ }^{\wedge}$ : according to the age-specific range; $\bullet$ preoperative; $\bullet$ : preoperative and intraoperative; $\bullet$ intraoperative.

\section{Results}

\subsection{Search and Selection}

Details related to the search process are shown in Figure 2. We were able to identify 31 boys in this retrospective cohort study. Twenty-six boys were diagnosed with a GCT $(83.9 \%)$, four boys with a SCST $(12.9 \%)$, and one boy with a gonadoblastoma $(3.2 \%)$. The proposed algorithm to aid in the decision for TSS versus RIO, based on the results of our recent systematic review, is depicted in Figure 1 [19].

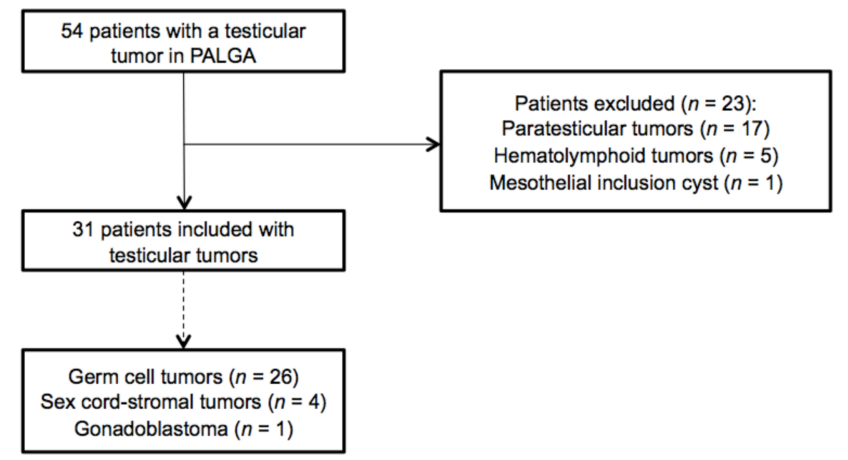

Figure 2. Flowchart of included and excluded patients during the search process.

\subsection{Clinical Characteristics}

Table 1 gives an overview of the clinical characteristics of the 31 included boys. The median age at presentation was 5.5 years (range $=0.0-16.9$ ). An enlarged testis $(61.3 \%)$ was the most common presentation, followed by scrotal pain $(19.4 \%)$, a palpable mass $(16.1 \%)$, and cryptorchidism (3.2\%). All boys had US examination at presentation, with the exception of an infant with gonadoblastoma who had Denys-Drash syndrome and was treated for cryptorchidism. During surgery, the right testicle appeared macroscopically abnormal and therefore was removed. 
Table 1. Clinical characteristics of the study population.

\begin{tabular}{cc}
\hline \multicolumn{2}{c}{ Patient Characteristics } \\
\hline Number of Patients & 31 \\
Median age in years (range) & $5.5(0-16.9)$ \\
Presenting Symptoms & \\
Enlarged testis & $19(61.3 \%)$ \\
Scrotal pain & $6(19.4 \%)$ \\
Palpable mass & $5(16.1 \%)$ \\
Cryptorchidism & $1(3.2 \%)$ \\
Side (left/right) & $13 / 18$ \\
Imaging & \\
US & 13 \\
US + CT & 12 \\
US + MRI & 2 \\
US + CT + MRI & 3 \\
None & 1 \\
Median follow-up in months (range) & $34(5-94)$ \\
\hline
\end{tabular}

Cross-sectional imaging of the abdomen, using CT and/or MRI, was performed in one boy with a Sertoli cell tumor (SCT) and in 16 boys with a proven malignant GCTs, based on histopathological diagnosis to complete staging. Of the boys with benign GCTs and SCSTs, the median follow-up time was 17 months (range = 5-94). However, three boys had no follow-up data: one boy was referred to another center for follow-up, one boy had no follow-up, and in one boy the reason for lack of follow-up was unclear. Of the boys with malignant tumors, the median follow-up time was 43 months (range $=5-55$ ). One boy was referred to another center for follow-up, resulting in no data to include.

\subsection{Diagnostic Findings, Treatment, and Outcome}

Table 2 shows the diagnostic findings, initial treatment, and outcome of the 31 boys with a testicular tumor. Benign GCTs were diagnosed in prepubertal boys (median age $=5.8$ years), with the exception of one pubertal boy (13 years) with a dermoid cyst. In two boys, AFP levels were elevated compared to age-specific ranges. Both presented with a mature teratoma and immature components, without the presence of a yolk sac tumor (YST). AFP levels normalized after resection. Eventually, four boys were treated with TSS, including three mature teratomas and a dermoid cyst. Other GCTs were treated with RIO. No recurrence was found during follow-up. 
Table 2. Stage of disease, pubertal status, diagnostic findings, TSS, use of FSE, adjuvant treatment, and outcome for boys with a testicular tumor.

\begin{tabular}{|c|c|c|c|c|c|c|c|c|c|c|}
\hline $\begin{array}{l}\text { Histopathological } \\
\text { Diagnosis }\end{array}$ & Stage * & $\begin{array}{l}\text { Median Age in } \\
\text { Years (Range) }\end{array}$ & Pubertal Status & $\begin{array}{l}\text { Findings on Imaging } \\
\text { (US/CT/MRI) }\end{array}$ & $\begin{array}{c}n(\%) \text { with } \\
\text { Elevated AFP }\end{array}$ & $\begin{array}{c}n(\%) \text { with } \\
\text { Elevated bHCG }\end{array}$ & $\begin{array}{l}\text { Surgical } \\
\text { Approach }\end{array}$ & FSE & $\begin{array}{l}\text { Adjuvant } \\
\text { Treatment }\end{array}$ & Outcome \\
\hline \multicolumn{11}{|c|}{ GCTs } \\
\hline \multicolumn{11}{|c|}{ Benign } \\
\hline MT & I (4) & $5.3(2.8-5.8)$ & Pre (4) & $\begin{array}{c}\text { Suspected of benign } \\
\text { pathology (3), inconclusive on } \\
\text { US (1) }\end{array}$ & $0(0 \%)$ & $0(0 \%)$ & TSS (3), RIO (1) & Yes (2), no (2) & None (4) & NED (4) \\
\hline $\mathrm{MT}+\mathrm{IT}$ & I (2) & 5.5 & Pre (2) & $\begin{array}{l}\text { Suspected of malignancy (1), } \\
\text { inconclusive on US (1) }\end{array}$ & $2(100 \%)$ & $0(0 \%)$ & RIO (2) & No (2) & None (1), ND (1) & NED (1), ND (1) \\
\hline $\mathrm{EpC}$ & $\mathrm{I}(1)$ & 11.7 & Pre (1) & Inconclusive on US (1) & $0(0 \%)$ & $0(0 \%)$ & RIO (1) & No (1) & None (1) & ND (1) \\
\hline DC & $\mathrm{I}(2)$ & 10.9 & Pre (1), Pub (1) & $\begin{array}{l}\text { Suspected of benign } \\
\text { pathology (2) }\end{array}$ & $0(0 \%)$ & $0(0 \%)$ & TSS (1), RIO (1) & No (2) & None (2) & NED (2) \\
\hline \multicolumn{11}{|c|}{ Malignant } \\
\hline YST & $\mathrm{I}(10)$ & $1.4(0.3-2.3)$ & Pre (10) & $\begin{array}{c}\text { Suspected of malignancy (3), } \\
\text { inconclusive on US (2), } \\
\text { inconclusive on US + CT (4), } \\
\text { inconclusive on US + MRI (1) }\end{array}$ & $10(100 \%)$ & $0(0 \%)$ & RIO (10) & Yes (2), no (8) & $\begin{array}{l}\text { None (3), BEP (1), } \\
\text { 2PE (6) }\end{array}$ & $\operatorname{NED}(9), \operatorname{ND}(1)$ \\
\hline \multirow[b]{2}{*}{ MGCT } & II (1) & 0.4 & Pre (1) & Suspected of malignancy (1) & $1(100 \%)$ & $0(0 \%)$ & $\mathrm{SO}(1)$ & No (1) & $4 \mathrm{PEI}+\mathrm{RLND}(1)$ & NED (1) \\
\hline & I (4) & $15.4(14.5-16.4)$ & $\operatorname{Pub}(4)$ & $\begin{array}{l}\text { Suspected of malignancy (2), } \\
\text { inconclusive on US + CT (2) }\end{array}$ & $3(75 \%)$ & $3(75 \%)$ & $\mathrm{RIO}(4)$ & No $(4)$ & $\begin{array}{c}\text { 2PE (2), 2PEI (1), } \\
1 \mathrm{PE}+2 \mathrm{PEI}(1)\end{array}$ & NED (4) \\
\hline \multicolumn{11}{|c|}{ SCSTs } \\
\hline SCT & I (2) & 4.9 & Pre (2) & $\begin{array}{c}\text { Inconclusive on US (1), } \\
\text { inconclusive on US + MRI (1) }\end{array}$ & $0(0 \%)$ & $0(0 \%)$ & RIO (1), SO (1) & No (2) & None (2) & NED (2) \\
\hline JGCT & $\mathrm{I}(2)$ & 0.2 & Pre (2) & Inconclusive on US (2) & $1(50 \%)$ & $1(50 \%)$ & $\mathrm{RIO}(2)$ & Yes $(1)$, no (1) & None (2) & NED (2) \\
\hline \multicolumn{11}{|c|}{ GCT/SCST } \\
\hline Gonadoblastoma & $\mathrm{I}(1)$ & 0 & Pre (1) & ND & ND & ND & RIO (1) & No (1) & None (1) & NED (1) \\
\hline
\end{tabular}

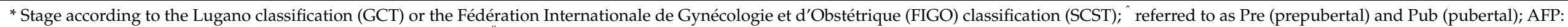

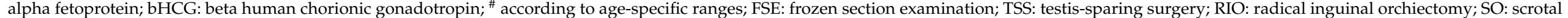

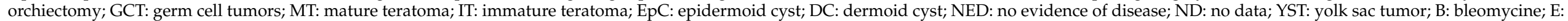
etoposide; P: cisplatin; I: ifosfamide; J: carboplatin; RLND: retroperitoneal lymph node dissection; SCT: Sertoli cell tumor; JGCT: juvenile granulosa cell tumor; NA: not applicable. 
Among the 17 malignant GCTs (median age $=1.5$ years) were 11 prepubertal YSTs (median age $=1.4$ years) and six pubertal MGCTs (median age $=16.3$ years). All boys with a YST presented with elevated AFP levels and normal bHCG concentrations. In boys with MGCTs, both AFP and bHCG were elevated, with the exception of one boy in whom both STMs appeared normal. All boys were treated with a radical resection, generally with RIO. A scrotal orchiectomy (SO) was performed in a 5-month-old boy with a stage II YST after initial scrotal exploration. All boys with malignant GCTs received platinum-based chemotherapy postoperatively. In two cases of MGCT and one case of YST, postoperative adverse events were described, including wound infection, bleeding and hematoma. No evidence of disease was reported in any of the boys during follow-up.

Of the four boys with an SCST (median age $=0.2$ years), two had SCTs and showed normal STMs. The other two had juvenile granulosa cell tumors (JGCTs), of which one boy showed slightly elevated AFP levels and the other boy showed abnormal bHGC levels. One boy with an SCT was treated with SO, while the other three SCSTs were treated with RIO. No patient received adjuvant treatment. No recurrence or progression of disease occurred during follow-up.

\subsection{Performance, Considerations, and Outcome of TSS}

Table 3 presents boys who, based on their histopathological diagnosis, would have been eligible for TSS according to the algorithm depicted in Figure 1. All boys were less than 12 years of age, except for patient \#1. Patients \#1 to \#4, who were diagnosed with a dermoid cyst and mature teratoma, were treated with TSS. STMs were normal, and US findings were suggestive of benign pathology. The considerations regarding the technical feasibility were only described in the medical records of patient \#3. Diagnosis of the testicular tumor of patients \#2 and \#4 was initially determined based on FSE, and both were subsequently confirmed by final histopathological diagnosis. No postoperative complications from TSS occurred, except for the scrotal abscess of patient \#3, which was treated with inguinal exploration. No cases of recurrence or testicular atrophy presented during follow-up.

Patients \#5 to \#13 were retrospectively considered for TSS using the algorithm. Four boys had elevated STMs (\#6, \#7,\#12, and \#13), two testicular tumors were assessed as technically unfeasible (\#5 and \#8), one affected testicle was considered to be non-functioning (\#9), and in one boy MRI could not rule out malignancy (\#10). Eventually, TSS might have been an option in one infant with an SCT displaying with normal (age-specific) STMs and inconclusive US findings (\#11). Thus, boys with potentially benign pathology have been treated according to the algorithm, except for one boy (patient \#11), who might have been eligible for treatment with TSS. 
Table 3. Characteristics of boys with a benign GCT or SCST in which TSS could have been considered, based on their histopathology, according to the algorithm.

\begin{tabular}{|c|c|c|c|c|c|c|c|c|c|c|c|}
\hline Patient Number & $\begin{array}{l}\text { Age in } \\
\text { Years }\end{array}$ & $\begin{array}{c}\text { AFP } \\
\text { Level }\end{array}$ & $\begin{array}{l}\text { bHCG } \\
\text { Level }\end{array}$ & Size on US * & Findings on US & Considerations against TSS & $\begin{array}{c}\text { Surgical } \\
\text { Approach }\end{array}$ & FSE & Final Pathology & $\begin{array}{l}\text { Testicular } \\
\text { Atrophy }\end{array}$ & $\begin{array}{l}\text { Postoperative } \\
\text { Complications }\end{array}$ \\
\hline 1 & 13.8 & 1.9 & $<2.0$ & $1.3 \times 1.8 \times 1.3$ & $\begin{array}{c}\text { Suspected of } \\
\text { benign pathology }\end{array}$ & None & TSS & No & Dermoid cyst & No & None \\
\hline 2 & 6 & 1.0 & $<2.0$ & ND & $\begin{array}{c}\text { Suspected of } \\
\text { benign pathology }\end{array}$ & None & TSS & Yes & Mature teratoma & No & None \\
\hline 3 & 2.2 & 2.5 & $<2.0$ & ND & $\begin{array}{c}\text { Suspected of } \\
\text { benign pathology }\end{array}$ & None & TSS & No & Mature teratoma & No & Abscess \\
\hline 4 & 4.9 & 2.0 & $<2.0$ & $0.7 \times 0.8 \times 0.8$ & $\begin{array}{c}\text { Suspected of } \\
\text { benign pathology }\end{array}$ & None & TSS & Yes & Mature teratoma & No & None \\
\hline 5 & 5.8 & $<1.0$ & $<2.0$ & $2.0 \times 1.3 \times 2.0$ & Inconclusive & $\begin{array}{l}\text { Technically unfeasible, } \\
\text { according to } \\
\text { attending physician }\end{array}$ & RIO & No & Mature teratoma & NA & None \\
\hline 7 & 0.4 & $45.9^{\#}$ & $<2.0$ & $3.6 \times 2.6 \times 2.2$ & $\begin{array}{l}\text { Suspected of } \\
\text { malignancy }\end{array}$ & $\begin{array}{l}\text { Elevated AFP + suspected of } \\
\text { malignancy on US }\end{array}$ & RIO & No & $\begin{array}{l}\text { Mature teratoma with } \\
\text { immature components }\end{array}$ & NA & ND \\
\hline 8 & 11.7 & $<2.0$ & $<2.0$ & $1.1^{\wedge}$ & Inconclusive & $\begin{array}{l}\text { Technically unfeasible, } \\
\text { according to } \\
\text { attending physician }\end{array}$ & RIO & No & Epidermoid cyst & NA & ND \\
\hline 9 & 8.1 & 1.2 & $<2.0$ & $2 \times 1.2 \times 3$ & $\begin{array}{c}\text { Suspected of } \\
\text { benign pathology }\end{array}$ & $\begin{array}{l}\text { Non-functioning testis, } \\
\text { according to } \\
\text { attending physician }\end{array}$ & RIO & No & Dermoid cyst & NA & None \\
\hline 10 & 9.8 & 2.0 & $<0.2$ & $1 \times 0.9 \times 0.7$ & Inconclusive & $\begin{array}{l}\text { MRI could not rule } \\
\text { out malignancy }\end{array}$ & SO & No & Sertoli cell tumor & NA & None \\
\hline 11 & 0 & 11,000 & $<2.0$ & $2.8 \times 2.0 \times 2.2$ & Inconclusive & None & RIO & No & Sertoli cell tumor & NA & None \\
\hline
\end{tabular}

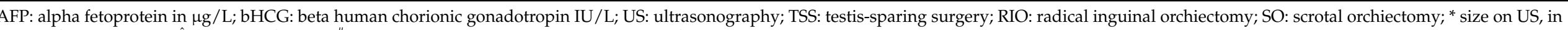
cm; FP: final pathology; ' diameter of tumor; ${ }^{\#}$ elevated AFP levels, according to age-specific ranges; NA: not applicable. 


\section{Discussion}

The purpose of the current retrospective study was to evaluate surgical treatment and outcome for boys with a testicular tumor treated in two pediatric hospitals. We focused specifically on boys who were treated with or would retrospectively have been eligible for TSS, using our previously proposed algorithm. We showed that boys with benign testicular tumors were treated in line with our algorithm, except for one boy who might, in retrospect, have been eligible for treatment with TSS as well.

With an incidence of 0.5-2.0 per 100,000 children, testicular tumors are rare [6]. For this reason, few single or multicenter studies and no randomized controlled trials regarding the treatment have been reported. Of the 31 boys with intratesticular tumors treated in our centers, the majority were GCTs $(83.9 \%)$, and to a lesser extent SCSTs $(12.9 \%)$ and gonadoblastoma (3.2\%), which is in line with the recently described epidemiology [21]. The histopathology appears to be distributed according to age, corresponding to the literature, in which prepubertal boys aged less than 12 mainly show teratomas and YSTs (type I GCTs), while adolescents are likely to show more aggressive MGCTs (type II GCTs) [12,22]. According to the epidemiology described by Chung et al., benign tumors generally form the clear majority (75\%) in the prepubertal population [23], while in our study $45.8 \%$ of the prepubertal children had a malignant tumor. The Princess Máxima Center for Pediatric Oncology is a tertiary center, and patients are only referred to this institution in case of a suspected malignancy. That might explain why our cohort contains relatively more malignant testicular tumors.

All boys received initial surgical treatment as advised in current guidelines [4,23]; among the patients, 25 had RIO (80.6\%), two had SO (6.5\%) and four had TSS (12.9\%). These surgical treatments appeared to be safe regarding recurrence and survival, since none of the boys showed evidence of disease or died during follow-up. Few postoperative complications were described, and no long-term sequelae. Testicular tumors resected by TSS all appeared benign and were found to retrospectively match most of the diagnostic findings described in the proposed algorithm, including negative STMs and benign characteristics on US. Nonetheless, one boy was older than 12 years of age (\#1), technical feasibility was not described in one boy (\#2), and intraoperative FSE was performed in only two boys (\#2 and \#4). Boys with benign pathology, in whom TSS was not performed, would also not have been eligible for TSS in retrospect, according to our algorithm, with the exception of one boy. In this particular patient, MRI or FSE might have been of additional value in the considerations of the application of TSS, knowing that FSE could harbor a risk of sampling error.

Some limitations regarding this study are to be noted. Variation between radiologists in reporting tumor characteristics as benign or malignant could risk bias. In addition, the attending physician also plays a major role in examination, decisions taken in the diagnostic process, request for additional imaging and documentation in medical files, and consequently risks of reporting bias. Furthermore, the changing view of the diagnostic process and treatment approach over time could also influence choices made in individual patients.

Regarding the generalization of results, it should be kept in mind that the population was partly obtained from a hospital specializing in pediatric oncology. Subsequently, the results may be biased, especially with regard to malignant/benign pathology ratio. The number of benign testicular tumors in a general pediatric center might therefore be higher, thereby increasing the potential and use of TSS. Nonetheless, while our recommendations are based on the results of patients treated in a center of expertise, the question remains as to what extent the application of TSS is feasible in general centers, which rarely treat pediatric testicular tumors. Prospective studies should therefore be performed in the future for validation.

We advise using STM and US for the primary purpose of tissue characterization, thereby distinguishing between benign and malignant. In cases of inconclusiveness regarding the benign characteristics, MRI could be considered. In addition, technical feasibility should always be actively considered and described pre- and intraoperatively. Moreover, 
FSE could be performed during TSS when the mentioned requirements for benign pathology are met, especially in combination with the currently developed direct enzymatic alkaline phosphatase reactivity (dAP) test. This diagnostic assessment technique directly evaluates the presence of carcinoma in situ, seminoma, or embryonal carcinoma [24].

Assessment of STMs is an essential component in the initial evaluation of patients showing a testicular mass, and the pattern of elevation may provide inside on the histopathological type of a testicular GCT [25]. In our cohort, only three boys with benign GCTs showed elevated AFP levels, including two mature teratomas with immature components and one JGCT. Levels of bHCG were only elevated in one boy with a JGCT. Malignant GCTs presented with either high AFP concentrations, in case of YSTs, or elevated AFP and bHCG in boys with MGCTs, with the exception of one boy with an MGCT ( $90 \%$ embryonal carcinoma, 10\% YST) presenting with normal STMs. Even though US is the imaging tool of choice for analysis of scrotal masses, due to its wide availability and high sensitivity, its specificity remains rather low [26], as has been shown in the current results. In addition, differences in reporting of tissue characterization using US led to many findings being considered inconclusive. In our population, CT was most often performed for the evaluation of intra-abdominal metastasis, while MRI was only used in the assessment of five testicular tumors. However, in general the preference is for using MRI, since one would like to minimize radiation exposure to children, and MRI seems to be more reliable for soft tissue assessment and therefore tissue characterization [27]. MRI might even support the evaluation of surgical feasibility [26].

In other studies, the decision to carry out TSS has depended on intraoperative FSE [28,29], while this has not been standardly performed in our patients. Matei et al. reported a sensitivity and specificity of $90 \%$ and $99 \%$, respectively, of FSE for benign tumors, which shows that FSE correlates well with the final diagnosis based on pathology [30], possibly even increasing when using the dAP staining technique [24]. Intraoperative FSE can be considered in the surgical procedure of TSS in patients with testicular tumors suspected of benign pathology. On the other hand, potential anxieties and over-testing should be avoided for lesions suggestive of benign pathology upon initial evaluation.

\section{Conclusions}

In conclusion, our retrospective analysis of surgical treatment of prepubertal boys with benign testicular tumors showed that TSS appears to be safe and should be considered based on clinicoradiological data, in line with our algorithm and hypothesis. Future prospective studies should provide further validation of the algorithm.

Author Contributions: Conceptualization, C.D.K., C.C.C.H., A.J.K., and A.M.C.M.-G.; methodology, C.D.K., C.C.C.H., A.J.K., and A.M.C.M.-G.; formal analysis, C.D.K., C.C.C.H., and A.M.C.M.-G.; writing-original draft preparation, C.D.K., C.C.C.H., and A.M.C.M.-G.; writing-review and editing, C.D.K., C.C.C.H., M.E.G.K., J.Z., A.S.L., L.H.J.L., A.J.K., and A.M.C.M.-G. All authors have read and agreed to the published version of the manuscript.

Funding: This research received no external funding.

Institutional Review Board Statement: The study was approved by the Institutional Board of the Princess Máxima Center for Pediatric Oncology.

Informed Consent Statement: This study was approved by the Medical Research Ethics Committee Utrecht (protocol code 20-499/C, 29 July 2020). Patient consent was waived due to minimal risk of the research involved.

Data Availability Statement: The data that support the findings of this study are available on request from the corresponding author (A.M.C.M.-G.).

Conflicts of Interest: The authors declare no conflict of interest. 


\section{References}

1. Shanmugalingam, T.; Soultati, A.; Chowdhury, S.; Rudman, S.; van Hemelrijck, M. Global incidence and outcome of testic-ular cancer. Clin. Epidemiol. 2013, 5, 417-427. [PubMed]

2. Purdue, M.P.; Devesa, S.S.; Sigurdson, A.J.; McGlynn, K.A. International patterns and trends in testis cancer incidence. Int. J. Cancer 2005, 115, 822-827. [CrossRef] [PubMed]

3. Cheng, L.; Albers, P.; Berney, D.M.; Feldman, D.R.; Daugaard, G.; Gilligan, T.; Looijenga, L.H. Testicular cancer. Nat. Rev. Dis. Primers 2018, 4, 1-24. [CrossRef] [PubMed]

4. Maizlin, I.I.; Dellinger, M.; Gow, K.W.; Goldin, A.B.; Goldfarb, M.; Nuchtern, J.G.; Langer, M.; Vasudevan, S.A.; Doski, J.J.; Raval, M.V.; et al. Testicular tumors in prepubescent patients. J. Pediatr. Surg. 2018, 53, 1748-1752. [CrossRef] [PubMed]

5. Karmazyn, B.; Weatherly, D.; Lehnert, S.J.; Cain, M.; Fan, R.; Jennings, S.G.; Ouyang, F.; Kaefer, M. Characteristics of testicular tumors in prepubertal children (age 5-12 years). J. Pediatr. Urol. 2018, 14, 259.e1-259.e6. [CrossRef]

6. Ahmed, H.U.; Arya, M.; Muneer, A.; Mushtaq, I.; Sebire, N.J. Testicular and paratesticular tumours in the prepubertal pop-ulation. Lancet Oncol. 2010, 11, 476-483. [CrossRef]

7. Hung, G.-Y.; Horng, J.-L.; Yen, H.-J.; Lee, C.-Y. Pre-pubertal and adolescent germ cell neoplasms in Taiwan: Time trends and geographic variation. Andrology 2015, 3, 895-901. [CrossRef]

8. Looijenga, L.H.; Van der Kwast, T.H.; Grignon, D.; Egevad, L.; Kristiansen, G.; Kao, C.S.; Idrees, M.T. Report From the International Society of Urological Pathology (ISUP) Consultation Conference on Mo-lecular Pathology of Urogenital Cancers. Am. J. Surg. Pathol. 2020, 44, e66-e79.

9. Spiller, C.M.; Bowles, J. Germ cell neoplasia in situ: The precursor cell for invasive germ cell tumors of the testis. Int. J. Biochem. Cell Biol. 2017, 86, 22-25. [CrossRef]

10. Moch, H.; Cubilla, A.L.; Humphrey, P.A.; Reuter, V.E.; Ulbright, T.M. The 2016 WHO Classification of Tumours of the Urinary System and Male Genital Organs_-Part A: Renal, Penile, and Testicular Tumours. Eur. Urol. 2016, 70, 93-105. [CrossRef]

11. Pohl, H.G.; Shukla, A.R.; Metcalf, P.D.; Cilento, B.G.; Retik, A.B.; Bagli, D.J.; Huff, D.S.; Gil Rushton, H. Prepubertal Testis Tumors: Actual Prevalence Rate of Histological Types. J. Urol. 2004, 172, 2370-2372. [CrossRef] [PubMed]

12. Calaminus, G.; Schneider, D.T.; von Schweinitz, D.; Jürgens, H.; Infed, N.; Schönberger, S.; Olson, T.A.; Albers, P.; Vokuhl, C.; Stein, R.; et al. Age-Dependent Presentation and Clinical Course of 1465 Patients Aged 0 to Less than 18 Years with Ovarian or Testicular Germ Cell Tumors; Data of the MAKEI 96 Protocol Revisited in the Light of Prenatal Germ Cell Biology. Cancers 2020, 12, 611. [CrossRef] [PubMed]

13. Patel, H.D.; Gupta, M.; Cheaib, J.G.; Sharma, R.; Zhang, A.; Bass, E.B.; Pierorazio, P. Testis-sparing surgery and scrotal violation for testicular masses suspicious for malignancy: A systematic review and meta-analysis. Urol. Oncol. Semin. Orig. Investig. 2020, 38, 344-353. [CrossRef] [PubMed]

14. Woo, L.L.; Ross, J.H. The role of testis-sparing surgery in children and adolescents with testicular tumors. Urol. Oncol. Semin. Orig. Investig. 2016, 34, 76-83. [CrossRef] [PubMed]

15. Djaladat, H. Organ-sparing surgery for testicular tumours. Curr. Opin. Urol. 2015, 25, 116-120. [CrossRef] [PubMed]

16. Zuniga, A.; Lawrentschuk, N.; Jewett, M.A. Organ-sparing approaches for testiclar masses. Nat. Rev. Urol. 2010, 7, 454-464. [CrossRef]

17. Ferreira, U.; Netto, N.R.; Esteves, S.C.; Rivero, M.A.; Schirren, C. Comparative Study of the Fertility Potential of Men with only one Testis. Scand. J. Urol. Nephrol. 1991, 25, 255-259. [CrossRef]

18. Radford, A.; Peycelon, M.; Haid, B.; Powis, M.; Lakshminarayanan, B. Testicular-sparing surgery in the pediatric popula-tion: Multicenter review of practice with review of the literature. Curr. Opin. Urol. 2019, 29, 481-486. [CrossRef]

19. Kooij, C.D.; Hulsker, C.C.; Kranendonk, M.E.; Zsiros, J.; Littooij, A.S.; Looijenga, L.H.; Klijn, A.J.; Mavinkurve-Groothuis, A.M. Testis Sparing Surgery in Pediatric Testicular Tumors. Cancers 2020, 12, 2867. [CrossRef]

20. Overbeek, L.; Van Kemenade, F.; Meijer, G. Het Pathologisch-Anatomisch Landelijk Geautomatiseerd Archief. Tijdschr. Voor Gezondh. 2012, 90, 276-279. [CrossRef]

21. Kusler, K.A.; Poynter, J.N. International testicular cancer incidence rates in children, adolescents and young adults. Cancer Epidemiol. 2018, 56, 106-111. [CrossRef] [PubMed]

22. Nistal, M.; Paniagua, R.; González-Peramato, P.; Reyes-Múgica, M. Perspectives in pediatric pathology, chapter 25. Testic-ular and paratesticular tumors in the pediatric age group. Pediatr. Dev. Pathol. 2016, 19, 471-492. [CrossRef] [PubMed]

23. Chung, J.M.; Lee, S.D. Overview of Pediatric Testicular Tumors in Korea. Korean J. Urol. 2014, 55, 789-796. [CrossRef] [PubMed]

24. Stoop, H.; Kirkels, W.; Dohle, G.R.; Gillis, A.J.M.; Bakker, M.A.D.; Biermann, K.; Oosterhuis, J.W.; Looijenga, L.H. Diagnosis of testicular carcinoma in situ' (intratubular and microinvasive)' seminoma and embryonal carcinoma using direct enzymatic alkaline phosphatase reactivity on frozen histological sections. Histopathology 2011, 58, 440-446. [CrossRef] [PubMed]

25. Barlow, L.J.; Badalato, G.M.; McKiernan, J.M. Serum tumor markers in the evaluation of male germ cell tumors. Nat. Rev. Urol. 2010, 7, 610-617. [CrossRef]

26. Mittal, P.K.; Abdalla, A.S.; Chatterjee, A.; Baumgarten, D.A.; Harri, P.A.; Patel, J.; Moreno, C.C.; Gabriel, H.A.; Miller, F.H. Spectrum of Extratesticular and Testicular Pathologic Conditions at Scrotal MR Imaging. Radiographics 2018, 38, 806-830. [CrossRef] 
27. Pearce, M.; Salotti, J.A.; Little, M.P.; McHugh, K.; Lee, C.; Kim, K.P.; Howe, N.L.; Ronckers, C.M.; Rajaraman, P.; Craft, A.W.S.; et al. Radiation exposure from CT scans in childhood and subsequent risk of leukaemia and brain tumours: A retrospective cohort study. Lancet 2012, 380, 499-505. [CrossRef]

28. Hisamatsu, E.; Takagi, S.; Nakagawa, Y.; Sugita, Y.; Yoshino, K.; Ueoka, K.; Tanikaze, S. Prepubertal testicular tumors: A 20-year experience with 40 cases. Int. J. Urol. 2010, 17, 956-959. [CrossRef]

29. Friend, J.; Barker, A.; Khosa, J.; Samnakay, N. Benign scrotal masses in children-some new lessons learned. J. Pediatr. Surg. 2016, 51, 1737-1742. [CrossRef]

30. Matei, D.V.; Vartolomei, M.D.; Renne, G.; Tringali, V.M.L.; Russo, A.; Bianchi, R.; Cozzi, G.; Bottero, D.; Musi, G.; Mazzarol, G.; et al. Reliability of Frozen Section Examination in a Large Cohort of Testicular Masses: What Did We Learn? Clin. Genitourin. Cancer 2017, 15, e689-e696. [CrossRef] 